\title{
Penghentian Prematur Atas Prosedur Audit Pada Kantor Akuntan Publik (KAP) di Semarang
}

\author{
NURDHIANA \\ WENNY ANAADNANTI \\ FEBY KRISTIYANI \\ Jurusan Akuntansi, Sekolah Tinggi Ilmu Ekonomi Widya Manggala \\ Jalan Sriwijaya No. 32 \& 36 Semarang 50242 \\ Email: nurdhiana27@gmail.com
}

Diterima 20 Februari 2019; disetujui 27 Februari 2019;

\begin{abstract}
The research was aimed to analyse the influence of time pressure, audit risk, materiality, review procedure and quality control, locus of control, self esteem in relation to ambition, turn over intention to premature sign-off of audit procedure. The population of this research were 243 auditors who worked at Public Accountant Firm in Semarang. While the samples of this research are 113 auditors. The technique sampling in this research is non probability sampling with purposive sampling method based of judgement sampling. The analysis technique used was multiple linear regression. The result of this research indicates that time pressure, locus of control, and turn over intention have positive significant influence on premature sign-off of audite procedure, but audit risk, materiality, review procedure and quality control, and self esteem in relation to ambition didn't have influence on premature sign-off of audite procedure.
\end{abstract}

Keywords: premature sign-off of audite procedure, time pressure, and locus of control

\section{PENDAHULUAN}

Latar Belakang. Proses audit merupakan bagian dari assurance services, pengauditan ini melibatkan usaha peningkatan kualitas informasi dari pihak yang melakukan audit, sehingga kesalahan yang terjadi dalam proses pengauditan akan berakibat pada berkurangnya kualitas informasi yang diterima oleh pengambil keputusan (Suryanita et al, 2007). Profesi akuntan publik hadir untuk memberikan penilain atas kendala (reliability) informasi akuntansi yang disajikan perusahaan dalam laporan keuangan, maka pengujian oleh akuntan publik melalui proses audit diperlukan guna menetralisir bias yang melekat pada informasi tersebut, sehingga laporan yang telah dinyatakan wajar oleh akuntan publik akan berisi informasi yang reliabel.
Penghentian prematur atas prosedur audit merupakan salah satu perilaku pengurangan kualitas audit. (Malone dan Roberts, 1996; dalam Wibowo, 2008). Berkaitan dengan penghentian terhadap prosedur audit yang dapat digambarkan sebagai tindakan tidak melakukan pekerjaan secara lengkap dan mengabaikan prosedur audit tetapi auditor berani mengungkap opini atas laporan keuangan yang mereka audit. Ada beberapa alasan mengapa auditor melakukan penghentian prematur atas prosedur audit: (a) Terbatasnya jangka waktu pengauditan yang ditetapkan, (b) Anggapan bahwa prosedur audit yang dilakukan tidak perlu, (c) Terbatasnya waktu penyampaian laporan audit, dan (f) Faktor kebosanan audit (Alderman \& Deitrick, 1982; dalam Berdasarkan alasan - alasan tersebut dapat disimpulkan penghentian prematur atas prosedur audit disebabkan oleh faktor karakteristik 
personal auditor, dimana faktor karakteristik tersebut merupakan faktor internal dan faktor situasional saat melakukan audit merupakan faktor eksternal (Weningtyas dkk, 2006).

Beberapa penelitian yang meneliti tentang penghentian prematur atas prosedur audit menemukan hasil yang berbeda Sitorus (2016), Yusrawati dan Suryadi (2009) menemukan hasil variabel time pressure dan resiko audit berpengaruh positif signifikan terhadap penghentian premature atas prosedur audit berbeda dengan penelitian yang dilakukan oleh Wahyudi dkk (2016) yang menemukan hasil variabel time pressure dan resiko audit tidak berpengaruh, Taufiq (2012) menemukan hasil variabel locus of control berpengaruh terhadap penghentian premature atas prosedur audit sedangkan Budiman (2013) variabel locus of control dan materialitas tidak berpengaruh terhadap penghentian prematur atas prosedur audit.

Tujuan Penelitian. Tujuan penelitian ini untuk mengetahui pengaruh time pressure, resiko audit, materialitas, prosedur review dan kontrol kualitas, locus of control, self esteem in relation to ambition, dan turn over intention terhadap penghentian prematur atas prosedur audit.

\section{TINJAUAN TEORETIS}

Teori Atribusi. Ikhsan dan Ishak (2005) menjelaskan bahwa teori atribusi mempelajari proses bagaimana seseorang menginterpretasikan suatu peristiwa, alasan, atau sebab perilakunya. Teori ini dikembangkan oleh Fritz Heider yang berargumentasi bahwa perilaku seseorang ditentukan oleh kombinasi antara kekuatan internal yaitu faktorfaktor yang berasal dari dalam diri seseorang, seperti kemampuan dan usaha, dan kekuatan eksternal yaitu faktor-faktor yang berasal dari luar seperti kesulitan dalam pekerjaan.

Teori Keagenan. Teori keagenan menjelaskan adanya konflik antara auditor selaku agent dan pimpinan KAP sebagai principal. Principal yaitu pimpinan KAP ingin agar KAP yang dimilikinya mendapatkan klien dan pendapatan semaksimal mungkin dengan cara memberi tugas auditor mengaudit lebih dari satu klien dalam waktu bersamaan dan juga memberi mereka tuntutan agar dapat menyelesaikan tugasnya dalam waktu yang telah ditetapkan. Sedangkan agent yaitu auditor seharusnya setiap mereka melakukan tugas audit, mereka harus melakukannya sesuai dengan prosedur audit yang telah ditetapkan dalam Pernyataan Standar Auditing (PSA). Karena adanya perbedaan keinginan inilah yang mengakibatkan auditor mendapat banyak pekerjaan dan tidak memiliki waktu yang cukup sehingga kemungkinan untuk melakukan penghentian preamtur atas prosedur audit akan timbul.

Penghentian Prematur Atas Prosedur Audit. Penghentian prematur atas prosedur audit sebagai suatu keadaan yang menunjukkan auditor menghentikan satu atau beberapa langkah audit yang diperlukan dalam prosedur audit (Akbari, 2015).

Time Pressure. Time pressure merupakan kondisi dimana auditor mendapatkan tekanan dari Kantor Akuntan Publik untuk menyelesaikan audit tepat pada waktunya dan anggaran biaya yang telah ditentukan sebelumnya (Akbari, 2015).

Risiko Audit. Dalam penelitian ini resiko audit yang dimaksud adalah resiko deteksi, resiko deteksi adalah resiko sebagai akibat auditor tidak dapat mendeteksi salah saji material yang terdapat dalam suatu asersi. Hal ini dikarenakan resiko ini menyatakan ketidakpastian yang dihadapi auditor. Dimana kemungkinan bahan bukti yang telah dikumpulkan oleh auditor tidak mampu untuk mendeteksi adanya salah saji material (Kumalasari, 2013).

Materialitas. Materialitas merupakan besarnya informasi akuntansi yang apabila terjadi penghilangan atau salah saji, dilihat dari keadaan yang melingkupinya, dapat mengubah atau mempengaruhi pertimbangan orang yang meletakkan kepercayaan terhadap informasitersebut (SA Seksi 312).

Prosedur Review dan Kontrol Kualitas. Prosedur review berperan sebagai bukti pendukung yang telah lengkap dan kontrol kualitas memastikan bahwa pada pelaksanaan prosedur audit telah sesuai standar auditing (Kumalasari,2013).

Locus of Control. Locus of control tergolong menjadi dua yaitu locus of control internal dan locus of control eksternal. Dalam penelitian ini hanya mengacu pada locus of control eksternalnya saja. Locus of control eksternal adalah tingkatan 
dimana seseorang individu berharap bahwa hasil perilaku mereka bergantung pada fungsi dari kesempatan, keberuntungan atau takdir di bawah kendali yang lain atau tidak bisa diprediksi (Akbari, 2015).

Self Esteem in Relation to Ambition. Self esteem (harga diri) adalah tingkatan dimana individu menyukai atau tidak menyukai diri mereka sendiri. Individu dengan harga diri yang berkaitan dengan ambisi tinggi yakin bahwa mereka memiliki kemampuan yang mereka butuhkan untuk berhasil dalam bekerja. Hal ini dikarenakan ambisi dapat menjadi suatu sifat yang mendorong karyawan untuk menempuh cara apapun untuk mendapatkan penilaian evaluasi yang baik sebagai ukuran kinerja, bukannya secara riil meningkatkan kinerja (Akbari, 2015).

Turnover Intention. Turnover intention mencerminkan keinginan individu untuk meninggalkan organisasi dan mencari alternatif pekerjaan di tempat lain (Akbari,2015:7).

Kerangka Teoretis. Kerangka teoretis dalam penelitian ini mereplikasi penelitian dari Akbari, Nur
\& Hariyani (2015) yang dapat dilihat pada gambar 1 .

Hipotesis. Berdasarkan tinjauan teoritis di atas, maka dalam penelitian ini disusun hipotesis sebagai berikut:

$\mathrm{Ha}_{1}$ : time pressure berpengaruh positif terhadap penghentian prematur atas prosedur audit.

$\mathrm{Ha}_{2}$ : resiko audit berpengaruh positif terhadap penghentian prematur atas prosedur audit.

$\mathrm{Ha}_{3}$ : materialitas berpengaruh negatif terhadap penghentian prematur atas prosedur audit

$\mathrm{Ha}_{4}$ : prosedur review dan kontrol kualitas berpengaruh negatif terhadap penghentian prematur atas prosedur audit.

$\mathrm{Ha}_{5}$ : locus of control eksternal berpengaruh positif terhadap penghentian prematur atas prosedur audit.

$\mathrm{Ha}_{6}$ : self esteem in relation to ambition berpengaruh positif terhadap penghentian prematur atas prosedur audit.

$\mathrm{Ha}_{7}$ : turn over intention berpengaruh positif terhadap penghentian prematur atas prosedur audit

\section{Gambar 1}

Pengaruh Faktor Situasional dan Faktor Personal Auditor Terhadap Premature Sign Off

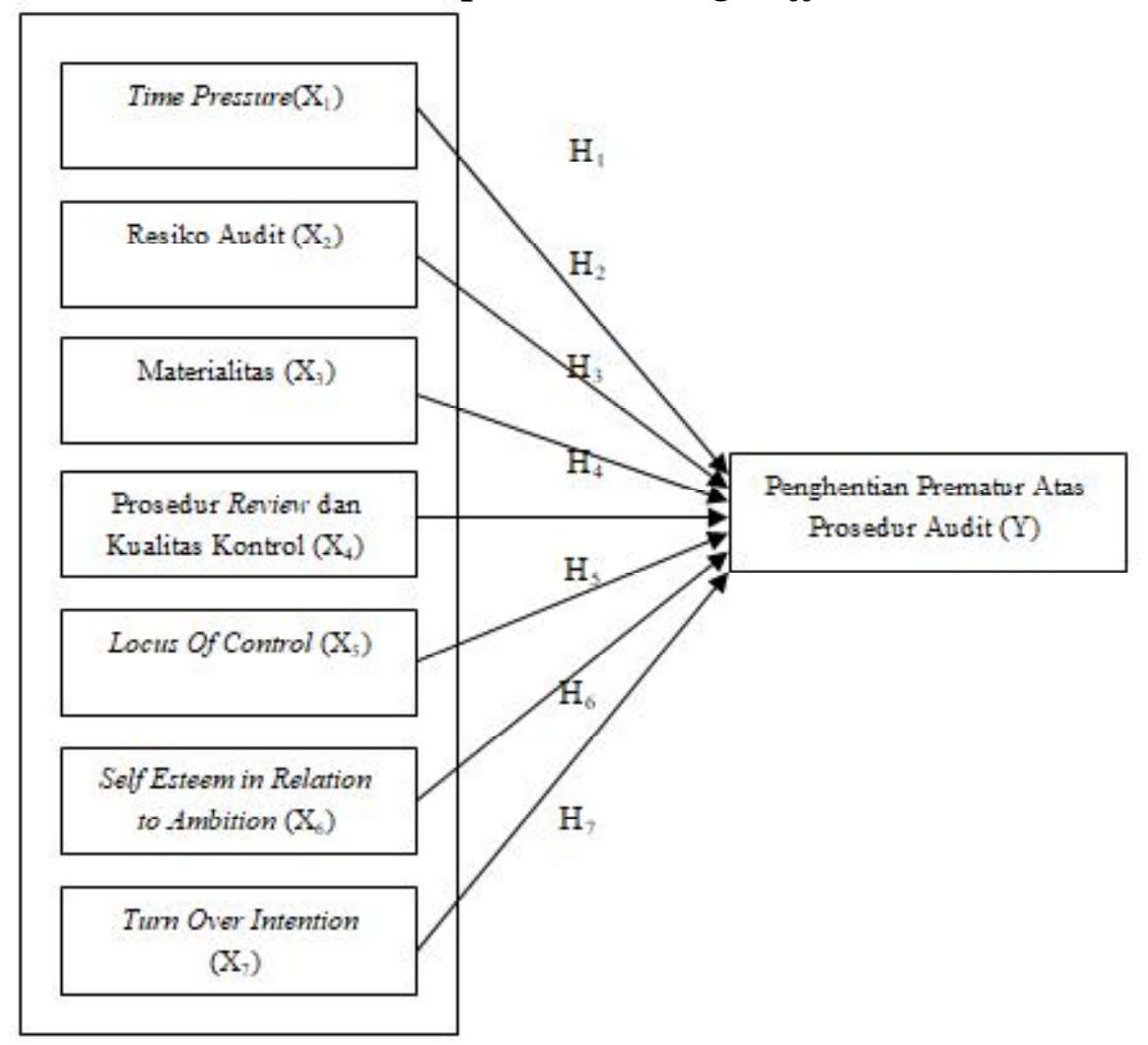




\section{METODE PENELITIAN}

Jenis Penelitian. Jenis penelitian ini dikategorikan ke dalam kausal komparatif, yaitu merupakan tipe penelitian dengan karakteristik masalah berupa hubungan sebab akibat antara dua variabel atau lebih (Indriantoro dan Supomo, 1999).

Definisi Operasional Variabel. Definisi operasional untuk masing-masing variabel adalah sebagai berikut:

\section{Penghentian PrematurAtas Prosedur Audit.}

Variabel ini diukur dengan indikator sebagai berikut:

a. Tidak memerlukan pemahaman bisnis klien dalamperencanaan audit.

b. Tidak mempertimbangkan SPI dalam audit laporan keuangan.

c. Tidak menggunakan informasi asersi dalam merumuskan tujuan audit dan merancang pengujian substantif.

d. Tidak menggunakan fungsi auditor internal dalam audit.

e. Tidak melakukan prosedur analitis dalam perencanaan dan review audit.

f. Tidak melakukan konfirmasi dengan pihak ketiga

g. Tidak menggunakan representasi manajemen dalam audit.

h. Tidak melakukan uji kepatuhan terhadap pengendalian atas transaksi dalam aplikasi computer on-line.

i. Tidak mengurangi jumlah sampel yang direncanakan dalam audit.

j. Tidak melakukan perhitungan fisik terhadap kas atau persediaan.

2. Time Pressure. Indikator yang digunakan untuk mengukur variabel ini terdiri dari:

a. Anggaran waktu dalam audit kurang.

b. Mengaudit beberapa perusahaan dalam periode bersamaan.

c. Melanggar anggaran waktu yang telah direncanakan dalam audit.

d. Lembur dalam audit.

e. Menyediakan waktu cadangan untuk hal-hal yang tak terduga dalam audit.

3. Resiko Audit. Variabel risiko audit diukur dengan beberapa indicator, diantaranya:

a. Tidak melakukan perhitungan fisik terhadap kas, investasi, persediaan dalam audit laporan keuangan merupakan tindakan beresiko tinggi.

b. Melakukan pengurangan jumlah sampel dalam melakukan audit merupakan tindakan beresiko tinggi.

c. Tidak melakukan konfirmasi dengan pihak ketiga merupakan tindakan beresiko tinggi.

4. Materialitas. Indikator pengukur variabel Materialitas antara lain:

a. Pengurangan jumlah sampel adalah tidak material.

b. Pemeriksaan fisik terhadap kas dan persediaan adalah tidak material.

c. Melakukan konfirmasi dengan pihak ketiga adalah hal tidak material.

\section{Prosedur Review dan Kontrol Kualitas}

Prosedur review berperan sebagai bukti pendukung yang telah lengkap dan kontrol kualitas memastikan bahwa pada pelaksanaan prosedur audit telah sesuai standar auditing.

Dimensi : Pelaksanaan prosedur audit sesuai standar auditing.

Indikator :

a. Terdapat auditor yang melakukan penghentian prematur maka tindakan tersebut akan ditemukan.

b. Auditor melakukan review dangkal pada dokumen klien, prosedur review dan kontrol kualitas di KAP tidak akan ditemukan.

c. Prosedur review dan kontrol kualitas yang terdapat dalam KAP tidak dapat menemukan kegagalan auditor dalam meneliti masalah teknis klien yang menurut auditor tidak meyakinkan.

d. Jika auditor menerima penjelasan yang lemah dari klien, proses review akan menemukan hal ini dan KAP akan mensyaratkan kerja tambahan.

e. KAP memiliki sistem kualitas kontrol yang efektif.

6. Locus Of Control. Variabel locus of control diukur dengan indicator sebagai berikut:

a. Memperoleh pekerjaan yang diinginkan merupakan keberuntungan

b. Dapat menghasilkan uang adalah keberuntungan (nasib baik).

c. Untuk memperoleh pekerjaan yang benar- 
benar bagus harus mempunyai anggota keluarga atau teman yang menduduki jabatan tinggi.

d. Promosi biasanya merupakan keberuntungan (nasib baik).

e. Menghasilkan banyak uang harus kenal orang yang tepat.

f. Diperlukan banyak nasib untuk menjadi karyawan yang berprestasi.

g. Perbedaan antara orang yang menghasilkan banyak uang dan sedikit uang adalah keberuntungan (nasib baik).

7. Self Esteem in Relation to Ambition.

Variabel ini diukur dengan indikator sebagai berikut:

a. Anda cenderung membina hubungan yang baik dengan rekan sekerja.

b. Menurut Anda aktualisasi diri harus dicapai.

c. Anda merasa organisasi ini dan rekan sekerja Anda membutuhkan Anda.

d. Anda ingin disukai dan dihormati oleh teman - teman sekerja Anda.

8. Turnover Intention. Variabel ini diukur dengan indikator sebagai berikut:

a. Auditor merasa bahwa kebijakan sistem promosi yang berlaku di KAP ini tidak fair, sehingga auditor ingin bekerja di tempat lain.

b. Auditor tidak yakin bahwa karirnya dapat terus meningkat bila masih bekerja di KAP ini.

c. Kedudukan auditor di KAP tidak jelas sehingga merasa lebih baik mencari pekerjaan di KAP lain.

d. Auditor merasa bahwa KAP ini tidak memperhatikan kesejahteraan karyawannya, sehingga auditor tidak betah dan ingin pindah ke KAP lain.

e. Auditor berpikir untuk keluar atau melamar kerja di tempat lain yang menawarkan gaji lebih tinggi.

Populasi dan Sampel. Populasi yang digunakan adalah para auditor yang bekerja di 17 KAP di Semarang dengan jumlah auditor sebesar 235 responden. Sedangkan sampel yang digunakan adalah auditor yang bekerja di KAP di Semarang dengan kriteria telah bekerja minimal 2 tahun dan berposisi sebagai staff atau supervisor sejumlah 113 auditor.
Teknik Pengambilan Sampel. Teknik pengambilan sampel adalah non probability sampling yaitu teknik pengambilan sampel yang tidak memberi peluang /kesempatan sama bagi setiap unsur atau anggota populasi untuk dipilih menjadi sampel. Metode yang digunakan dalam penelitian ini adalah metode purposive sampling yaitu merupakan tipe pemilihan sampel secara tidak acak yang informasinya diperoleh dengan menggunakan pemilihan sampel berdasarkan pertimbangan (judgement sample) (Indriantoro dan Supomo, 1999).

Sumber Data. Sumber data dalam penelitian ini berupa data primer. Data primer merupakan data dan informasi yang diperoleh langsung dari sumbernya, yaitu auditor yang bekerja di KAP di Kota Semarang.

Teknik Analisis Data. Pada penelitian ini data yang telah diperoleh akan dianalisis dengan analisis regresi linier berganda. Analisis regresi berganda digunakan untuk mengukur kekuatan hubungan antar dua variabel atau lebih dan juga menunjukkan arah hubungan antara variabel dependen dengan variabel independen (Ghozali, 2013).

$$
\begin{aligned}
& \mathrm{Y}=a+b 1 . \mathrm{X} 1+\mathrm{b} 2 . \mathrm{X} 2+\mathrm{b} 3 . \mathrm{X} 3+\mathrm{b} 4 . \mathrm{X} 4+ \\
& \mathrm{b} 5 . \mathrm{X} 5+\mathrm{b} 6 . \mathrm{X} 6+\mathrm{b} 7 . \mathrm{X} 7
\end{aligned}
$$

Dimana:

Y : Penghentian Prematur Atas Prosedur Audit $\alpha \quad$ : konstanta

b1-b5 : koefisiensi regresi

$\mathrm{X} 1 \quad$ :Time Pressure

$\mathrm{X} 2$ : Resiko Audit

X3 : Materialitas

X4 : Prosedur Review dan Kontrol Kualitas

X5 : Locus Of Control

X6 : Self Esteem in Relation to Ambition

X7 : Turn Over Intention

\section{HASIL DAN PEMBAHASAN}

Hasil Analisis Regresi Linier Berganda. Hasil analisis regresi linier berganda dapat dilihat pada tabel 1. Berdasarkan tabel 1 dapat disusun persamaan regresi sebagai berikut:

$\mathrm{Y}=1,450+0,546 \mathrm{X} 1-0,359 \mathrm{X} 2-0,042 \mathrm{X} 3-$ $0,143 \mathrm{X} 4+0,318 \times 5-0,345 \mathrm{X} 6+0,520$ X7 
Koefisien Determinasi. Besarnya nilai koefisien determinasi yang ditunjukkan oleh nilai Adjusted $R$ Square (lihat tabel 2) yaitu sebesar 0,708 , hal ini berarti bahwa penghentian prematur atas prosedur audit mampu dijelaskan oleh variabel independen yaitu time pressure, resiko audit, materialitas, prosedur review dan kontrol kualitas, locus of control, self esteem in relation to ambition, dan turn over intention sebesar $70,8 \%$ sedangkan sisanya sebesar 29,2\% dijelaskan oleh faktor lain yang tidak diteliti dalam penelitian ini.

Hasil Uji Hipotesis. Hasil pengujian hipotesis untuk masing-masing variabel bebas adalah sebegai berikut:

1. Pengujian Hipotesis Time Pressure $\left(X_{1}\right)$ Terhadap Penghentian Prematur Atas Prosedur Audit (Y). Berdasarkan tabel 1 dapat diperoleh nilai t sebesar 3,476 dengan signifikansi sebesar 0,001 atau lebih kecil dari 5\% sehingga dapat disimpulkan bahwa time pressure berpengaruh positif signifikan terhadap penghentian premature atas prosedur audit.

2. Pengujian Hipotesis Risiko Audit $\left(\mathrm{X}_{2}\right)$ Terhadap Penghentian Prematur Atas Prosedur Audit (Y). Berdasarkan tabel 1 dapat diperoleh nilai t sebesar -1,518 dengan signifikansi sebesar 0,134 atau lebih besar dari 5\% sehingga dapat disimpulkan bahwa risiko audit tidak berpengaruh terhadap penghentian premature atas prosedur audit.

3. Pengujian Hipotesis $M$ aterialitas $\left(X_{3}\right)$ Terhadap Penghentian Prematur Atas Prosedur Audit (Y). Berdasarkan tabel 1 dapat diperoleh nilai $t$ sebesar $-0,305$ dengan signifikansi sebesar 0,761 atau lebih besar dari 5\% sehingga dapat disimpulkan bahwa materialitas tidak berpengaruh terhadap penghentian premature atas prosedur audit.

4. Pengujian Hipotesis Prosedur Review dan Kontrol Kualitas $\left(\mathrm{X}_{4}\right)$ Terhadap Penghentian Prematur Atas Prosedur Audit (Y). Berdasarkan tabel 1 dapat diperoleh nilai $\mathrm{t}$ sebesar -0,682 dengan signifikansi sebesar 0,497 atau lebih besar dari 5\% sehingga dapat disimpulkan bahwa prosedur review dan kontrol kualitas tidak berpengaruh terhadap penghentian premature atas prosedur audit.

5. Pengujian Hipotesis Locus of Control $\left(\mathrm{X}_{5}\right)$ Terhadap Penghentian Prematur Atas Prosedur Audit (Y). Berdasarkan tabel 1 dapat diperoleh nilai t sebesar 2,526 dengan signifikansi sebesar 0,014 atau lebih kecil dari 5\% sehingga dapat disimpulkan bahwa locus of control berpengaruh positif signifikan terhadap penghentian premature atas prosedur audit.

6. Pengujian Hipotesis Self Esteem in Relation to Ambition $\left(\mathrm{X}_{6}\right)$ Terhadap Penghen-

Tabel 1

Hasil Analisis Regresi Linier Berganda

\begin{tabular}{|c|c|c|c|c|c|c|}
\hline & \multirow[t]{2}{*}{ Model } & \multicolumn{2}{|c|}{ Unstandardized Coefficients } & \multirow{2}{*}{$\frac{\text { Standardized Coefficients }}{\text { Beta }}$} & \multirow[t]{2}{*}{$\mathrm{t}$} & \multirow[t]{2}{*}{ Sig. } \\
\hline & & $\mathrm{B}$ & Std. Error & & & \\
\hline \multirow[t]{8}{*}{1} & (Constant) & 1.450 & .784 & & 1.849 & .069 \\
\hline & $\mathrm{TP}$ & .546 & .157 & .311 & 3.476 & .001 \\
\hline & RA & -.359 & .236 & -.160 & -1.518 & .134 \\
\hline & M & -.042 & .138 & -.025 & -.305 & .761 \\
\hline & PRKK & -.143 & .210 & -.060 & -.682 & .497 \\
\hline & LOC & .318 & .126 & .180 & 2.526 & .014 \\
\hline & $\mathrm{SE}$ & -.345 & .297 & -.118 & -1.162 & .249 \\
\hline & TOI & .520 & .115 & .401 & 4.528 & .000 \\
\hline
\end{tabular}

a. Dependent Variable: PPAPA

Tabel 2

Koefisien Determinasi

\begin{tabular}{lcccc}
\hline Model & $\mathrm{R}$ & R Square & Adjusted R Square & Std. Error of the Estimate \\
\hline 1 & $.857^{\mathrm{a}}$ & .734 & .708 & .25961 \\
\hline a. Predictors: (Constant), TP,RA,M,PRKK,LOC,SE,TOI &
\end{tabular}


tian Prematur Atas Prosedur Audit (Y). Berdasarkan tabel 1 dapat diperoleh nilai $\mathrm{t}$ sebesar -1,162 dengan signifikansi sebesar 0,249 atau lebih besar dari 5\% sehingga dapat disimpulkan bahwa self esteem in relation to ambition tidak berpengaruh terhadap penghentian premature atas prosedur audit.

7. Pengujian Hipotesis Turnover Intention $\left(\mathrm{X}_{7}\right)$ Terhadap Penghentian Prematur Atas Prosedur Audit (Y). Berdasarkan tabel 1 dapat diperoleh nilait sebesar 4,58 dengan signifikansi sebesar 0,000 atau lebih kecil dari 5\% sehingga dapat disimpulkan bahwa turnover intention berpengaruh positif signifikan terhadap penghentian premature atas prosedur audit.

\section{SIMPULAN}

Kesimpulan. Berdasarkan hasil penelitian di atas maka dapat ditarik kesimpulan sebagai berikut:

1. Time pressure $\left(\mathrm{X}_{1}\right)$ berpengaruh positif signifikan terhadap penghentian prematur atas prosedur audit pada KAP di Semarang.

2. Resiko audit $\left(X_{2}\right)$ tidak berpengaruh terhadap penghentian prematur atas prosedur audit pada KAP di Semarang.

3. Materialitas $\left(\mathrm{X}_{3}\right)$ tidak berpengaruh terhadap penghentian prematur atas prosedur audit pada KAP di Semarang.

4. Prosedur review dan kontrol kualitas $\left(\mathrm{X}_{4}\right)$ tidak berpengaruh terhadap penghentian prematur atas prosedur audit pada KAP di Semarang.

5. Locus of control $\left(\mathrm{X}_{5}\right)$ berpengaruh positif signifikan terhadap penghentian prematur atas prosedur audit pada KAP di Semarang.

6. Self esteem in relation to ambition $\left(\mathrm{X}_{6}\right)$ tidak berpengaruh terhadap penghentian prematur atas prosedur audit pada KAP di Semarang.

7. Turn over intention $\left(\mathrm{X}_{7}\right)$ berpengaruh positif signifikan terhadap penghentian prematur atas prosedur audit pada KAP di Semarang.

Saran. Atas dasar kesimpulan yang telah dikemukakan di atas, maka saran yang dapat diberikan dalam penelitian adalah sebagai berikut :

1. Saran untuk Kantor Akuntan Publik

Penelitian ini menemukan bukti bahwa beberapa auditor pada KAP di Semarang melakukan penghentian prematur atas prosedur audit yang disebabkan oleh adanya time pressure, locus of control dan turn over intention yang tinggi. Untuk itu agar tidak terjadi penghentian prematur atas prosedur audit yang dilakukan sebaiknya auditor mampu mengatur waktu yang baik dengan mencadangkan waktu sehingga apabila terjadi hal yang tidak terduga dalam audit, auditor mampu melaksanakan tugas dengan baik. Kantor Akuntan Publik dalam melakukan penugasan audit juga perlu terus mem-follow up klien agar klien bisa bekerja sama dengan cara memberikan file-file yang diperlukan auditor dalam mengaudit perusahaannya tepat waktu, sehingga auditor mampu bekerja tanpa perlu membuang-buang waktu dan dapat dimanfaatkan untuk tugas audit yang lainnya.

2. Saran untuk Penelitian yang Akan Datang

Penelitian ini hanya menggunakan sampel auditor yang bekerja di KAP wilayah Semarang yang terdiri dari $17 \mathrm{KAP}$, sehingga hasil dan kesimpulan tidak dapat disimpulkan untuk auditor seluruh Indonesia. Diharapkan penelitian selanjutnya dapat memperbanyak jumlah KAP yang menjadi sampel dan menambah variabel bebas lain misalnya komitmen profesional, pengalaman kerja, kesadaran etis dll.

\section{DAFTAR PUSTAKA}

Akbari, Akhirumi Zakiah, Emrinaldi Nur DP dan Eka Hariyani. 2015. Pengaruh Faktor Situasional dan Faktor Karakteristik Personal Auditor Terhadap Prematur Off Sign. Jom FEKON Vol.2 No.1. Pekanbaru.

Budiman, Nita Andriyani. 2013. Pengaruh Faktor Internal dan Eksternal Auditor Terhadap Penghentian Prematur atas Prosedur dan Kualitas Audit. Jurnal Akuntansi dan Manajemen, Vol. 24, No. 3,

Ghozali, Imam. 2013. Aplikasi Analisis Multivariate dengan Program SPSS. Semarang: Badan penerbit Universitas Diponegoro.

Herningsih, Sucahyo. 2002. Penghentian prematur atas prosedur audit : Studi empiris pada kantor akuntan publik. Wahana, Vol. 5, No. 2

Ikatan Akuntan Indonesia. 2009. Pernyataan Standar Akuntansi Keuangan. Salemba Empat. Jakarta.

Indriantoro, Nur, Bambang Supomo. 1999. Metodelogi Penelitian Bisnis untuk Akuntansi dan Manajemen. Yogyakarta: BPFE Yogyakarta. 
Irawati, Yuke. 2005. Hubungan Karakteristik Personal Auditor Terhadap Tingkat Penerimaan Penyimpangan Perilaku dalam Audit. SNA VIII. Solo.

Kumalasari,Nova, Dwi Handayani, dan Haris Wibisono. 2013. Pemengaruh Penghentian Prematur Atas Prosedur Audit di KAP Surabaya. Jurnal Riset Manajemen dan Akuntansi Vol. 1, No. 1. Surabaya.

Mujiono, Rohmad Suryani, Fauzan. 2016. Pengaruh Tekanan Waktu, Materialitas, dan Resiko Audit Terhadap Penghentian Prematur atas Prosedur Audit. Seminar Nasional dan 3rd call for Syariah Paper. Surakarta.

Mulyadi. 2002. Auditing 1 : Edisi Enam. Salemba Empat. Jakarta.

Sitorus, Santa Ulina, Zirman, dan Rusli. 2016.
Pengaruh Time Pressure, Audit Risk, Professional Commitment, Review Procedure and Quality Control dan Self Esteem in Relation to Ambition Terhadap Terjadinya Penghentian Prematur Atas Prosedur Audit. JOM Fekon, Vol.3, No. 1. Pekanbaru.

Wahyudi, Imam, Jurica Lucyanda, dan Loekman Suhud. 2011. Praktik Penghentian Prematur atas Prosedur Audit. Media Riset Akuntansi Vol. 01, No. 02. Jakarta.

Yusrawati dan Ari Suryadi. 2009. Pengaruh Time Pressure, Resiko Audit, Materialitas, Prosedur Review dan Kontrol Kualitas, serta locus of control Terhadap Penghentian Prematur Atas Prosedur Audit. Jurnal Ekonomi, Manajemen dan Akuntansi, Vol. 15, No. 1. Pekanbaru. 